Article

\title{
Preparation and Characterization of Chitosan Obtained from Shells of Shrimp (Litopenaeus vannamei Boone)
}

\author{
Rayane Santa Cruz Martins de Queiroz Antonino ${ }^{1, *}$, Bianca Rosa Paschoal Lia Fook ${ }^{1}$, \\ Vítor Alexandre de Oliveira Lima ${ }^{2}$, Raid Ícaro de Farias Rached ${ }^{1}$, \\ Eunice Paloma Nascimento Lima ${ }^{1}$, Rodrigo José da Silva Lima ${ }^{2}$, \\ Carlos Andrés Peniche Covas ${ }^{3}$ and Marcus Vinícius Lia Fook ${ }^{2}$ \\ 1 Academic Unit of Materials Engineering (UAEMat), Federal University of Campina Grande (UFCG), \\ Campina Grande 58429-900, PB, Brazil; biancafook@gmail.com (B.R.P.L.F); raidicaro@gmail.com (R.Í.d.F.R.); \\ eunicelima@outlook.com (E.P.N.L.) \\ 2 Academic Unit of Physics (UAF), Federal University of Campina Grande (UFCG), \\ Campina Grande 58429-900, PB, Brazil; vitorao.lima@gmail.com (V.A.d.O.L.); \\ rodrigo@df.ufcg.edu.br (R.J.d.S.L.); marcus.fook@pq.cnpq.br (M.V.L.F.) \\ 3 Centro de Biomateriales-Universidad de La Habana, Ave. Universidad s/n, La Habana 10600, Cuba; \\ cpeniche2015@yahoo.com \\ * Correspondence: rayane.scruz@gmail.com; Tel.: +55-83-2101-1845
}

Academic Editors: Hitoshi Sashiwa, David Harding and Keith B. Glaser Received: 5 April 2017; Accepted: 8 May 2017; Published: 15 May 2017

\begin{abstract}
The main source of commercial chitosan is the extensive deacetylation of its parent polymer chitin. It is present in green algae, the cell walls or fungi and in the exoskeleton of crustaceans. A novel procedure for preparing chitosan from shrimp shells was developed. The procedure involves two 10-minutes bleaching steps with ethanol after the usual demineralization and deproteinization processes. Before deacetylation, chitin was immersed in $12.5 \mathrm{M} \mathrm{NaOH}$, cooled down and kept frozen for $24 \mathrm{~h}$. The obtained chitosan was characterized using scanning electron microscopy (SEM), Fourier transform infrared spectroscopy (FTIR), UV, X-ray diffraction (XRD) and viscosimetry. Samples of white chitosan with acetylation degrees below $9 \%$ were obtained, as determined by FTIR and UV-first derivative spectroscopy. The change in the morphology of samples was followed by SEM. The ash content of chitosan samples were all below $0.063 \%$. Chitosan was soluble in $1 \%$ acetic acid with insoluble contents of $0.62 \%$ or less. XRD patterns exhibited the characteristic peaks of chitosan centered at 10 and 20 degrees in $2 \theta$. The molecular weight of chitosan was between 2.3 and $2.8 \times 10^{5} \mathrm{~g} / \mathrm{mol}$. It is concluded that the procedure developed in the present work allowed obtaining chitosans with physical and chemical properties suitable for pharmaceutical applications.
\end{abstract}

Keywords: chitosan; chitin; Litopenaeus vannamei Boone

\section{Introduction}

Chitosan is a linear polysaccharide of natural origin composed essentially of $\beta$ - $(1,4)$-linked glucosamine units (2-amino-2-deoxy- $\beta$-D-glucopyranose) together with some proportion of $N$-acetylglucosamine units (2-acetamino-2-deoxy- $\beta$-D-glucopyranose) (Figure 1). Chitosan is characterized by its biocompatibility, biodegradability and non-toxicity [1]. Its exceptional biological properties (antimicrobial, antibacterial and coagulating activities, bioadhesivity and wound healing capacity) have made it an excellent candidate for applications in cosmetics [2], medicine [1,3,4] and pharmacy [5], agriculture [6], chitosan in the preservation of agricultural commodities [7], the food industry [8] and waste water treatment [9], among many other industrial applications. 
Chitosan is soluble in dilute solutions of many organic and inorganic acids $(p H<6)$, due to the protonation of its amino groups. Its polycationic character allows it to interact with polyanions producing polyelectrolyte complexes [10]. It has excellent film forming ability and can also be prepared in films, fibers, hydrogels and micro/nanoparticles [11,12]. The $\mathrm{OH}$ and $\mathrm{NH}_{2}$ functionalities in chitosan's structure allows the preparation of diverse derivatives with improved properties for specific applications.

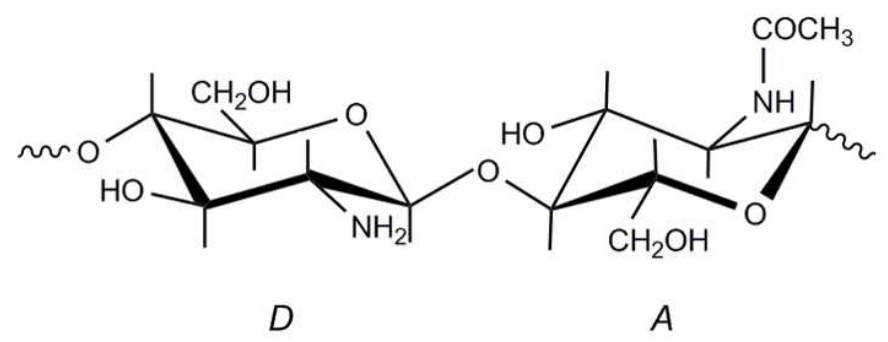

Figure 1. Structural units of chitin and chitosan. $(A) N$-acetylglucosamine unit; $(D)$ glucosamine unit. In chitosan, $(D)>(A)$; in chitin, $(A)>(D)$.

Chitosan is not extensively present in nature, although it can be found in in the Mucorales, in particular Mucor, Absidia and Rhizopus species [13]. The main source of commercial chitosan is the extensive deacetylation of its parent polymer chitin (Figure 1). Chitin is the second most abundant polysaccharide on earth, only preceded by cellulose. It is present in green algae, the cell walls or fungi, the cuticles of insects and arachnids and in the exoskeleton of crustaceans. At the industrial scale, the main source of chitin are the discarded remnants from crustacean (shrimp, prawn, crab and lobster) processing plants. The main components of crustacean shells are chitin (15-40\%), protein $(20-40 \%)$, calcium and magnesium carbonate $(20-50 \%)$, together with other minor constituents, such as astaxanthin, lipids and other minerals [14]. The isolation techniques reported are diverse, since they depend largely on the composition of the source, which varies considerably form one species to another [15]. Most of these techniques rely on chemical processes for extracting the protein and the removal of the inorganic matter. Some of them include a bleaching step by solvent extraction or by oxidation of the remaining pigments [16].

Demineralization of crustacean shells is usually carried out with dilute $\mathrm{HCl}$ solutions at room temperature, although other acids have also been used $\left(\mathrm{HNO}_{3}, \mathrm{H}_{2} \mathrm{SO}_{4}, \mathrm{CH}_{3} \mathrm{COOH}\right)$. The acid concentration and the time of treatment depend on the source of chitin, but, in any case, high temperatures are undesirable to prevent polymer degradation [17]. Alternative treatments to prevent degradation consist in the use of ethylenediaminetetraacetic acid (EDTA) [18] or ionic liquid extraction $[19,20]$. Lactic acid fermentation was used to extract chitin from prawn shells, but the product obtained a low quality chitin compared with the chemical extraction method [21]. Deproteinization of shrimp shells is often performed with dilute $\mathrm{NaOH}$ solutions at $65-100{ }^{\circ} \mathrm{C}$ from 0.5 to $72 \mathrm{~h}$. Some procedures involve two consecutive treatments for a short time, since long time periods or high temperatures can provoke chain scission and partial deacetylation of the polymer [17]. Enzymatic extracts or isolated enzymes and microbiological fermentation have been tested with some success [22], but the alternative of the enzymatic/microbiological treatment, besides being time-consuming, also usually leaves $1-7 \%$ of residual protein [23].

Deacetylation of chitin to produce chitosan is usually achieved by hydrolysis of the acetamide groups with concentrated $\mathrm{NaOH}$ or $\mathrm{KOH}(40-50 \%)$ at temperatures above $100{ }^{\circ} \mathrm{C}$. This reaction is generally carried out under heterogeneous conditions. The acetylation degree (DA) of chitosan, defined as the proportion of acetylglucosamine units in the polymer, will depend on the deacetylation conditions. It is very difficult to completely deacetylate chitin without using specific procedures, so that the DA of chitosans generally lies between $40 \%$ and $13 \%$, while its molecular weight ranges from $2 \times 10^{5}$ to $1 \times 10^{6} \mathrm{Da}$. The distribution of deacetylated units along the chitosan chain will 
also depend on the source and the preparation conditions [24]. Lertwattanaseri et al. reported that they needed to treat chitin whiskers lat reflux for $15 \mathrm{~h}$ in at least $40 \%$ alkaline solution to obtain chitosan with a DA below 10\% [25]. In the same paper, these authors showed that, by applying the microwave technique to chitin whiskers, it was possible to achieve chitosans with DA lower than $10 \%$ in only $3 \mathrm{~h}$ using a $60 \%(w / v)$ alkali concentration. Biotechnological processes based on the enzymatic deacetylation of chitin have been proposed as an alternative to minimize the effects of the chemical route. Some enzymes called chitin deacetylases are used for hydrolyzing the $\mathrm{N}$-acetamide bonds in order to obtain chitosan [26]. These enzymes can be obtained from some species of fungi and insects such as Mucor rouxii, Aspergillus nidulans, Absidia coerulea and Colletotrichum lindemuthianum. Obtaining chitosan by enzymatic reactions is an alternative for greater control of the properties and characteristics of the final product, such as degree of acetylation and average molecular mass. It is an alternative that is still at the laboratory scale, due to the sensitivity of the processing [15].

There are several reports in the literature on the preparation of chitin and chitosan from shrimp shells [27-31], but, as indicated above, the quality of the resulting chitosan was very dependent on the raw material and the particular procedure employed. Lamark et al. developed a multistep procedure to obtain fully deacetylated chitin preforming freeze-pump out-thaw (FPT) cycles (freezing at $-193{ }^{\circ} \mathrm{C}$ and thawing at $\left.25^{\circ} \mathrm{C}\right)$ in the presence of $50 \%(w / v) \mathrm{NaOH}$, with deacetylation temperatures ranging from 80 to $110{ }^{\circ} \mathrm{C}$. The FPT cycles improved the reaction effectiveness by opening the crystalline structure of chitin, making it more permeable to alkaline solutions. This increased the accessibility of the acetylated units to the alkali and facilitated their deacetylation [32].

The shrimp species Litopenaeus vannamei Boone is abundant in breeding sites in northeastern Brazil, and industrial processing plants generate considerable amount of discards. This waste is a protein- and chitin-rich pollutant that can be valued if a method of extracting these shell components is designed and implemented.

In the present work, we developed a new procedure for the preparation of chitosan from shrimp (Litopenaeus vannamei Boone) by introducing a step in which chitin is frozen at $-83{ }^{\circ} \mathrm{C}$ in the presence of $12.5 \mathrm{M} \mathrm{NaOH}$ before deacetylation in order to increase reaction efficiency. This method was able to achieve DA lower than $10 \%$. The chitosan obtained was characterized using scanning electron microscopy (SEM), Fourier transform infrared spectrometry (FTIR), UV-visible spectroscopy (UV) and $\mathrm{X}$-ray diffraction $(\mathrm{XRD})$.

\section{Materials and Methods}

Shells of marine Pacific whiteleg shrimp (Litopenaeus vannamei Boone) were obtained from Fazenda Aquamaris S.A (João Pessoa-PB, Brazil). Figure 2 shows a schematic representation of the production of chitosan from shrimp. The shells were washed thoroughly with water to remove impurities in a hot-air oven at $90^{\circ} \mathrm{C}$ for $6 \mathrm{~h}$. For chitin and chitosan productions, shells were homogenized in a blender into small sized pieces ( $<20$ mesh). This material was kept frozen until used. Acetate of sodium $\mathrm{C}_{2} \mathrm{H}_{3} \mathrm{NaO}_{2}$ were obtained from Grupo Química, Lot: 1093 (São Paulo, Brazil). Acetic acid glacial $\mathrm{CH}_{3} \mathrm{COOH}$ were obtained from Neon, Lot: 21352 (São Paulo, Brazil). Cloridric acid was obtained from Isofar, Lot: 141861 (Rio de Janeiro, Brazil). Sulfuric acid $\mathrm{H}_{2} \mathrm{SO}_{4}$ was obtained from Synth, Lot: 151095 (São Paulo, Brazil). Potassium bromide $\mathrm{KBr}$ was obtained from Neon, Lot: 3166 (São Paulo, Brazil). Ethanol $\mathrm{C}_{2} \mathrm{H}_{6} \mathrm{O}$ was obtained from Toscano, Lot: 259 (Santa Rita, Brazil). Sodium hydroxide $\mathrm{NaOH}$ were obtained from Neon, Lot: 21025 (São Paulo, Brazil). $\mathrm{N}$-acetylglucosamine $\mathrm{C}_{8} \mathrm{H}_{15} \mathrm{NO}_{6}$ was obtained from Sigma Aldrich, Lot: SLBF8809V (Missouri, TX, USA). 


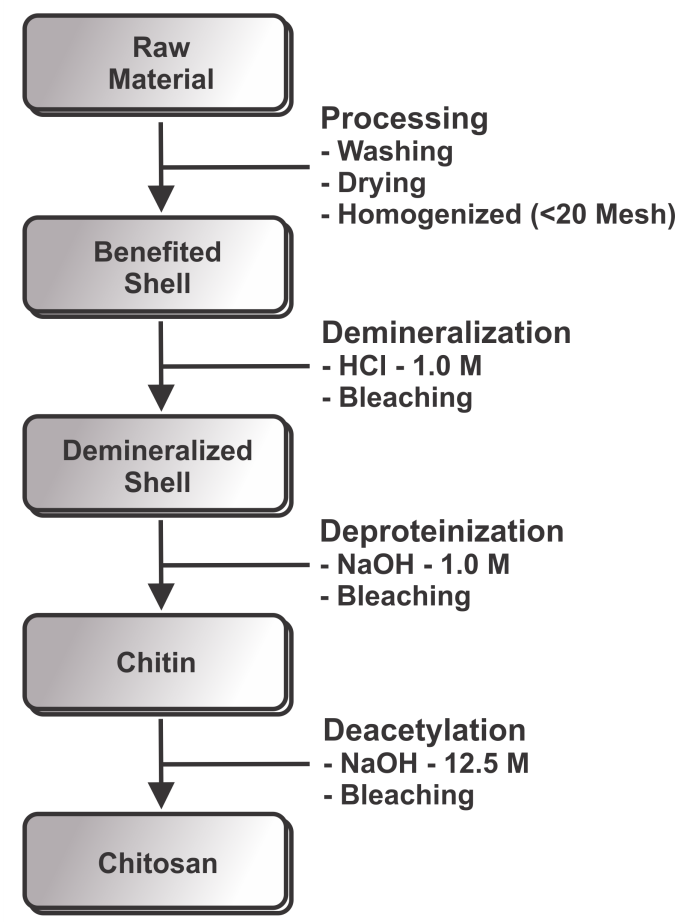

Figure 2. Schematic representation of the production of chitosan from shrimp.

\subsection{Demineralization}

Demineralization was carried out by adding $1 \mathrm{~L}$ of $1 \mathrm{M} \mathrm{HCl}$ to $100 \mathrm{~g}$ of shrimp shells. The reaction proceeded at room temperature under agitation at $250 \mathrm{rpm}$ for predetermined times $(0.5,2$, or $6 \mathrm{~h})$. Afterwards, the demineralized shells were filtrated and washed with distilled water until neutral $\mathrm{pH}$. They were bleached by immersing in ethanol for $10 \mathrm{~min}$ and dried in an oven at $70{ }^{\circ} \mathrm{C}$.

\subsection{Deproteinization}

Deproteinization was performed by adding $1 \mathrm{M} \mathrm{NaOH}$ to the dried demineralized shells at a solid/liquid ratio of 1:10 (g/mL). Reaction was carried out under agitation at $80{ }^{\circ} \mathrm{C}$ for $3 \mathrm{~h}$. The solid was filtrated and washed with distilled water until it achieved neutral $\mathrm{pH}$. Then, it was immersed in ethanol for $10 \mathrm{~min}$ for further bleaching, and the resulting chitin was dried in an oven at $70{ }^{\circ} \mathrm{C}$.

\subsection{Chitosan Production}

Deacetylation of chitin was achieved by reacting chitin with $12.5 \mathrm{M} \mathrm{NaOH}$ at a solid/liquid ratio of $1: 15(\mathrm{~g} / \mathrm{mL})$. The reaction mixture was cooled down and kept frozen at $-83{ }^{\circ} \mathrm{C}$ in an ultra-freezer for $24 \mathrm{~h}$. Afterwards, the temperature of the mixture was raised to $115^{\circ} \mathrm{C}$, and the reaction proceeded with agitation at $250 \mathrm{rpm}$ for 4 or $6 \mathrm{~h}$. The resulting chitosan was filtrated, washed with distilled water until neutral $\mathrm{pH}$ and dried in an oven at $70{ }^{\circ} \mathrm{C}$.

\subsection{Characterization of Samples}

\subsubsection{Sulfated Ash and Insuluble Content}

The amount of inorganics in samples was determined as described in the Brazilian Pharmacopeia [33]. Briefly, $1 \mathrm{~g}$ of sample was placed in a porcelain crucible previously ignited and weighed. The sample was moistened with $1 \mathrm{~mL}$ of concentrated $\mathrm{H}_{2} \mathrm{SO}_{4}$ and gently heated until the sample was thoroughly charred. After cooling, another $1 \mathrm{~mL}$ of $\mathrm{H}_{2} \mathrm{SO}_{4}$ was added to the crucible. The crucible was heated lightly to $(600 \pm 50){ }^{\circ} \mathrm{C}$ and maintained at this temperature until the residue became completely incinerated. 
The crucible was cooled in a desiccator and weighed. The operation of heating and cooling was repeated until constant weight was obtained. The content of sulfated ashes was calculated as

$$
\text { Sulfated } \operatorname{Ash}(\%)=\frac{\left(W_{2}-W_{1}\right)}{W} \times 100,
$$

where $W, W_{1}$ and $W_{2}$ are the weights of the sample taken for the test, the ignited crucible and the ignited residue with the crucible. Determinations were performed in triplicate and the results reported are the average values.

The solubility of chitosan was tested in dilute solutions of $1 \%$ acetic acid at $25^{\circ} \mathrm{C}$. The insoluble content was determined in triplicate, as established in ASTM F2103-11 [34]. Briefly, chitosan was dissolved in $1 \%$ of acetic acid at $25^{\circ} \mathrm{C}$ and the solution was filtered. Insoluble content was calculated form the weight of chitosan dissolved and the weight of insoluble particles obtained on the filter.

\subsubsection{Scanning Electron Microscopy}

Morphology of samples was inspected using a Hitachi scanning electron microscope model TM-1000 (Tokyo, Japan) operated at an acceleration voltage of $15 \mathrm{kV}$. The microscope is equipped with an energy dispersive spectroscopy (EDS) detector (Oxford instruments, Oxford, UK). The samples for SEM were prepared by depositing onto carbon tape.

\subsubsection{Viscosity Average Molecular Weight}

Viscosity average molecular weight $\left(M_{v}\right)$ was obtained by determining the intrinsic viscosity $[\eta]$ of chitosan solutions in $0.3 \mathrm{M}$ acetic acid/0.2 $\mathrm{M}$ sodium acetate at $25^{\circ} \mathrm{C}$ using a previously reported method [35]. Determinations were performed in triplicate using an Ubbelohde type viscometer and $M_{v}$ was calculated using the Mark-Houwink-Sakurada equation:

$$
[\eta]=K M_{v}^{a} .
$$

In this chitosan-solvent system, $K=0.076 \mathrm{~mL} / \mathrm{g}$ and $a=0.76$.

\subsubsection{Degree of Acetylation}

The degree of acetylation (DA) was determined in triplicate by Fourier Transform Infrared Spectroscopy (FTIR). FTIR spectra were recorded at room temperature using a 400 Perkin Elmer spectrometer (Perkin-Elmer, Norwalk, CA, USA) from $4000 \mathrm{~cm}^{-1}$ to $400 \mathrm{~cm}^{-1}$. Samples were thoroughly dried and ground with $\mathrm{KBr}$ at a sample $/ \mathrm{KBr}$ ratio of 1:60. Discs were prepared by compression under vacuum. Spectra were obtained with a resolution of $2 \mathrm{~cm}^{-1}$ and were averaged over 100 scans. DA was calculated from the spectra using Equations (3)-(5), as proposed by Domszy and Roberts and Brugnerotto et al. [18,36], respectively:

$$
\begin{gathered}
D A(\%)=\left(\frac{A_{1655}}{A_{3450}}\right) \times 100 / 1.33, \\
D A(\%)=\left(\frac{A_{1655}}{A_{3450}}\right) \times 115, \\
\frac{A_{1320}}{A_{1420}}=0.3822-0.03133 D A(\%) .
\end{gathered}
$$

In these equations, $A_{1655}, A_{3450}, A_{1320}$ and $A_{1420}$ represent the absorbance of chitosan at 1655 , 3450,1320 and $1420 \mathrm{~cm}^{-1}$, respectively.

The DA was also determined in triplicate by the first derivative ultraviolet spectrophotometry method as described by Muzzarelli and Rochetti [37]. The principle of this method was based on the 
absorbance of the intensity of the $\mathrm{N}$-acetyl group in chitosan. The method requires the determination of a standard curve produced from varying concentrations of $N$-acetylglucosamine. DA was calculated from recordings of the first derivative of the UV spectra of $N$-acetylglucosamine and of chitosan samples at $202 \mathrm{~nm}$. Measurements were performed with a Cary 50 Bio Varian spectrophotometer (Palo Alto, CA, USA) with a 190-240 nm scan range. Far UV quartz cuvettes with $1 \mathrm{~cm}$ path length were used.

\subsubsection{X-ray Diffraction}

Crystallinity of samples was evaluated by wide angle X-ray diffraction (WAXD) analysis using an XRD 7000 Shimadzu (Shimadzu, Kyoto, Japan) difractometer operated with $\mathrm{Cu} \mathrm{K} \alpha$ radiation $(\lambda=0.15418 \mathrm{~nm})$. Diffraction patterns were recorded over a $2 \theta$ range of $5^{\circ}-40^{\circ}$ in continuous mode. The step size was $0.02^{\circ}$. The crystallinity index $(\mathrm{CrI})$ was obtained from the ratio of the area of the crystalline contribution $\left(A_{\text {crist }}\right)$ to the total area of the diffractogram $\left(A_{\text {total }}\right)$ as proposed by Osorio-Madrazo et al. [38]. For doing so, $A_{\text {crist }}$ was first obtained by subtracting the amorphous contribution from $A_{\text {total }}$ :

$$
\% C r I=100 \times A_{\text {crist }} / A_{\text {Total }} .
$$

\section{Results and Discussion}

\subsection{Sulfated Ash and Insoluble Content}

Chitosan samples were prepared with the different reaction conditions chosen. They were labeled as shown in Table 1 . All chitosan were obtained as white powders evidencing the efficiency of the bleaching treatments performed after the demineralization and deproteinization steps.

Table 1. Sulfated ash and insoluble content of chitosan samples prepared with the reaction times indicated. Deproteinization time was $3 \mathrm{~h}$ in all cases.

\begin{tabular}{ccccc}
\hline Sample & $\begin{array}{c}\text { Demineralization } \\
\text { Time (h) }\end{array}$ & $\begin{array}{c}\text { Deacetylation } \\
\text { Time (h) }\end{array}$ & $\begin{array}{c}\text { Sulfated Ash } \\
\mathbf{( \% )} \pm \text { SD }\end{array}$ & $\begin{array}{c}\text { Insoluble Content } \\
\mathbf{( \% )} \pm \text { SD }\end{array}$ \\
\hline CHI-1 & 6 & 4 & $0.063 \pm 0.042$ & $0.27 \pm 0.06$ \\
CHI-2 & 2 & 6 & $0.053 \pm 0.023$ & $0.30 \pm 0.11$ \\
CHI-3 & 0.5 & 6 & $0.010 \pm 0.002$ & $0.48 \pm 0.04$ \\
CHI-4 & 6 & 6 & $0.047 \pm 0.015$ & $0.62 \pm 0.23$ \\
\hline
\end{tabular}

\subsection{Scanning Electron Microscopy}

The morphology of the starting material and the effect of each reaction step on the morphology of samples were inspected by SEM. These are shown in Figure 3.

Shrimp shells exhibit a heterogeneous morphology characterized by a compact structure with well-defined round shaped white spots (Figure 3). EDS analysis of these spots (results not shown) indicated that they are composed almost exclusively by $\mathrm{CaCO}_{3}$. After demineralization, one can appreciate important changes in the surface of material. The white spots are now replaced by rounded holes resulting from the removal of $\mathrm{CaCO}_{3}$ by the acid treatment. EDS analysis showed the absence of $\mathrm{Ca}$ in the demineralized shells. In higher magnification, the fibrous nature of the material is revealed. The deproteinization step of the demineralized shells produced chitin. Its fibrous structure is also revealed in Figure 3. SEM micrographs of deacetylated sample CHI-4 also show the fibrous structure of the chitosan obtained. It is worth mentioning that all of the samples of the chitosan produced by processes employed to obtain chitosan (Table 1) exhibited similar morphological behavior. 

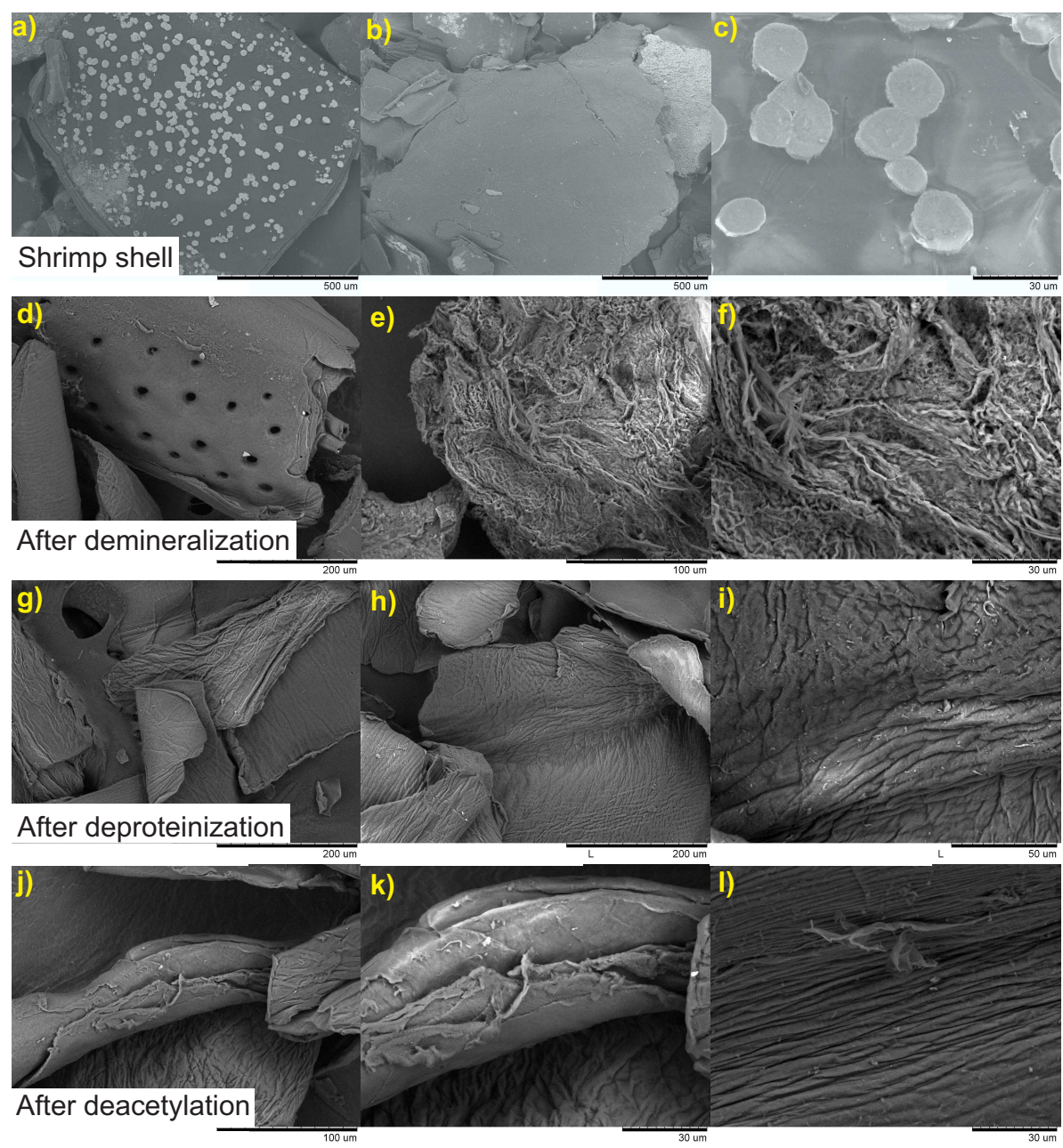

Figure 3. SEM micrographs of shrimp shells and the materials obtained with the processing conditions used for sample CHI-4 at three magnifications. Shrimp shell: (a) 200×; (b) 150×; (c) 2000×; after demineralization: (d) $500 \times$; (e) $1000 \times$; (f) 2000×; after deproteinization: (g) $500 \times$; (h) $500 \times$; (i) $1500 \times$; after deacetylation: (j) $1000 \times$; (k) $2000 \times$; (1) $2000 \times$.

All chitosans gave clear transparent solutions in $1 \%(v / v)$ acetic acid with very low insoluble content, as reported in Table 1 . The sulfated ash content was lower than $0.1 \%$ percent in all cases. These two parameters are within the requirements for chitosan applications in biomedical and tissue-engineered medical products $[39,40]$.

\subsection{Degree of Acetylation}

The FTIR spectra of the shell shrimp and chitin samples obtained are shown in Figure 4 and chitosan in Figure 5. Figure 4 shows $\alpha$-chitin characteristic bands such as: amide I band is split into two components at 1660 and $1630 \mathrm{~cm}^{-1}$ and amide II band is observed at $1558 \mathrm{~cm}^{-1}$. The $\mathrm{CH}$ deformation of the $\beta$-glycosidic bond is centered at $895 \mathrm{~cm}^{-1}$ [41]. Figure 5 exhibits the characteristic absorption bands at $3450 \mathrm{~cm}^{-1}$ (O-H stretching), $1870-2880 \mathrm{~cm}^{-1}$ (CH-stretching), $1655 \mathrm{~cm}^{-1}$ (Amide I), $1580 \mathrm{~cm}^{-1}$ (-NH $\mathrm{H}_{2}$ bending), and $1320 \mathrm{~cm}^{-1}$ (Amide III). The absorption bands at $1160 \mathrm{~cm}^{-1}$ (anti-symmetric stretching of the C-O-C bridge), 1082 and $1032 \mathrm{~cm}^{-1}$ (skeletal vibrations involving the C-O stretching) are characteristic of its saccharide structure [41]. 


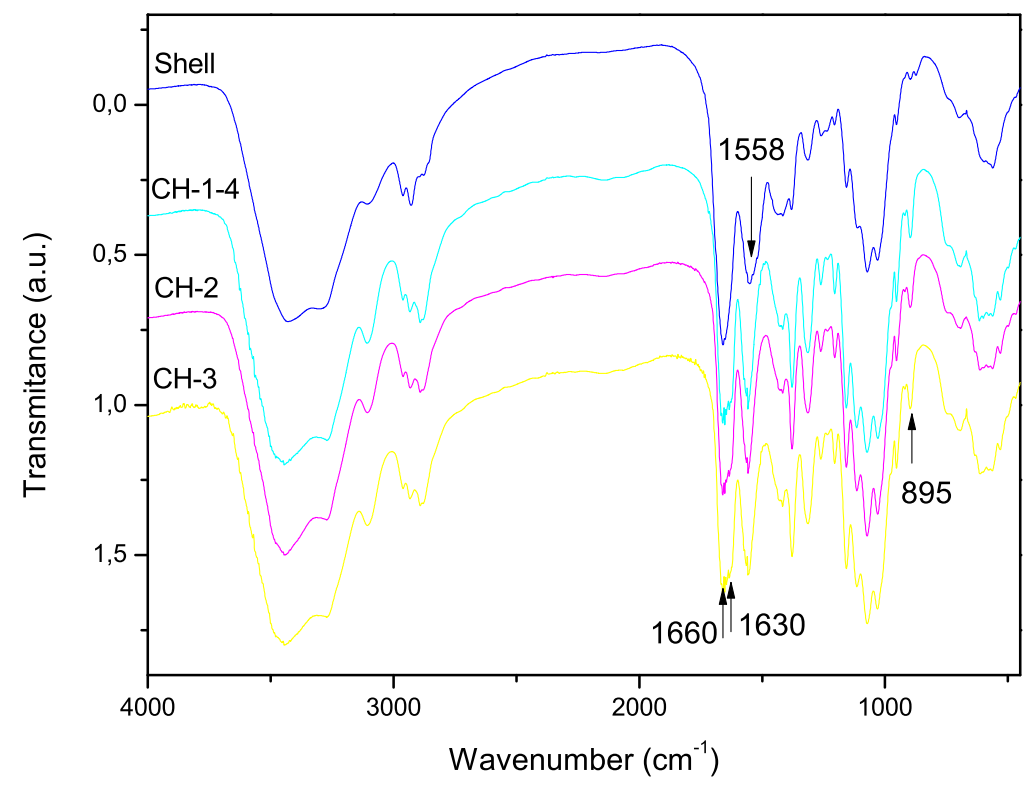

Figure 4. FTIR spectra of shell shrimp and chitin samples $\mathrm{CH}-1-4$ with demineralization of $6 \mathrm{~h}, \mathrm{CH}-2$ with demineralization of $2 \mathrm{~h}$ and $\mathrm{CH}-3$ with demineralization of $0.5 \mathrm{~h}$.

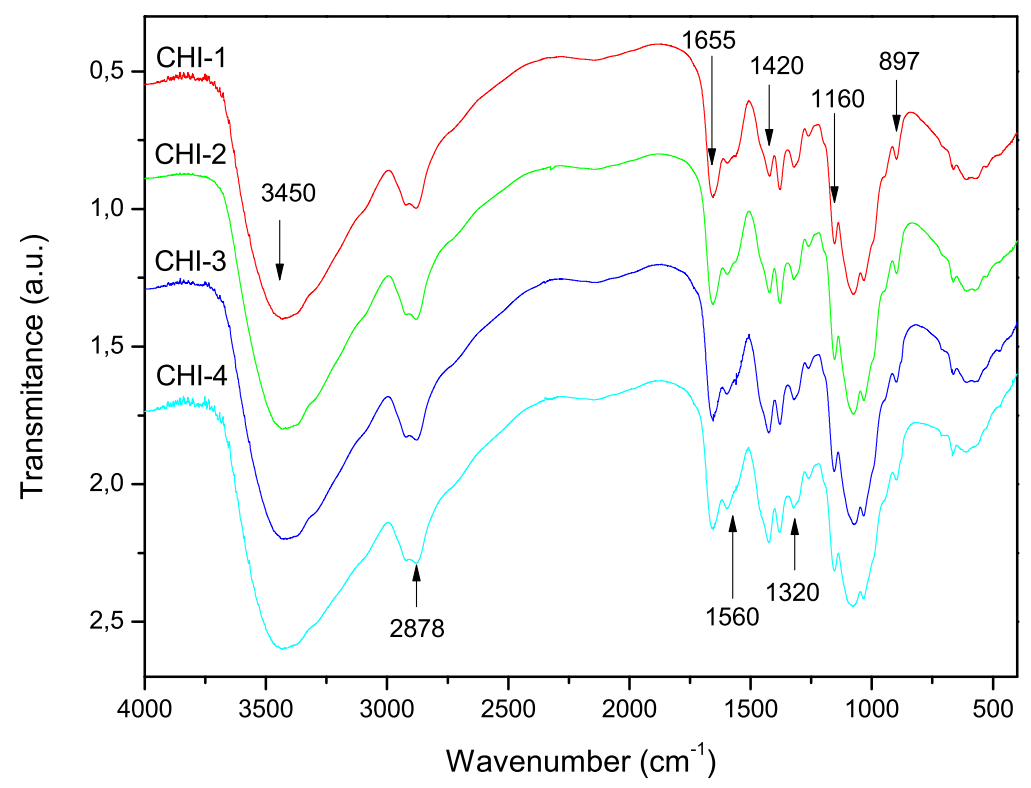

Figure 5. FTIR spectra of chitosan samples prepared with the reaction conditions listed in Table 1.

Equations (3)-(5) were used to determine the degree of acetylation of chitosan samples from the infrared spectra. The results are listed in Table 2, together with the acetylation degree obtained by UV-first derivative method. The degrees of acetylation were all below $9 \%$ for all samples. It is worth mentioning that the present procedure differs from other heterogeneous deacetylation procedures in that chitin samples are immersed in strong alkaline medium $(12.5 \mathrm{M} \mathrm{NaOH})$ and frozen for $24 \mathrm{~h}$ before starting deacetylation. This previous treatment must be responsible for the low acetylation values achieved in all cases. 
It is evident that the DA values obtained were dependent on the method of calculation. They are in the order Equation (3) < Equation (4) < Equation (5) < UV-first derivative. Since the latter has been recognized as the most sensitive of the proposed techniques for determining the DA of chitosan [42], the equation proposed by Brugnerotto et al. [18] resulted in the most appropriate one for determining the DA of these samples by FTIR.

Table 2. Degree of acetylation, DA (\%), of chitosans obtained from FTIR spectroscopy (Equations (3)-(5)) and the UV-first derivative method.

\begin{tabular}{|c|c|c|c|c|}
\hline \multirow{2}{*}{ Sample } & \multicolumn{3}{|c|}{ FTIR } & \multirow{2}{*}{$\begin{array}{c}\text { UV-First } \\
\text { Derivate } \pm \text { SD }\end{array}$} \\
\hline & Equation (3) \pm SD & Equation (4) \pm SD & Equation (5) \pm SD & \\
\hline CHI-1 & $2.7 \pm 0.2$ & $4.1 \pm 0.3$ & $7.9 \pm 0.5$ & $8.9 \pm 0.9$ \\
\hline CHI-2 & $2.6 \pm 0.5$ & $4.0 \pm 0.7$ & $7.8 \pm 0.9$ & $8.6 \pm 1.0$ \\
\hline CHI-3 & $2.5 \pm 0.3$ & $3.9 \pm 0.2$ & $8.1 \pm 0.2$ & $8.9 \pm 0.4$ \\
\hline CHI-4 & $2.5 \pm 0.8$ & $3.9 \pm 0.4$ & $7.6 \pm 1.2$ & $8.7 \pm 0.6$ \\
\hline
\end{tabular}

SD-Standard deviation.

\subsection{Viscosity Average Molecular Weight}

The intrinsic viscosity, [ $\eta$ ], of chitosan solutions in $0.3 \mathrm{M}$ acetic acid/ $0.2 \mathrm{M}$ sodium acetate at $25^{\circ} \mathrm{C}$ and the corresponding viscosity average molecular weight, $M_{v}$, were listed in Table 3 . The molecular weights of all samples were very similar in all cases, indicating that the various reaction conditions employed did not introduce substantial differences for the size of the chitosan chains.

Table 3. Intrinsic viscosity, $[\eta]$, viscositiy average molecular weight, $M_{v}$ and crystallinity index, $\mathrm{CrI}(\%)$ of chitosans.

\begin{tabular}{cccc}
\hline Sample & $[\boldsymbol{\eta}] \mathbf{( 1 0 0 ~} \mathbf{~ m L} / \mathbf{g}) \pm \mathbf{S D}$ & $\boldsymbol{M}_{\boldsymbol{v}}(\mathbf{g} / \mathbf{m o l})$ & $\mathbf{C r I} \mathbf{( \% )}$ \\
\hline CHI-1 & $1051 \pm 9$ & $2.8 \times 10^{5}$ & 45 \\
CHI-2 & $1030 \pm 19$ & $2.7 \times 10^{5}$ & 40 \\
CHI-3 & $898 \pm 19$ & $2.3 \times 10^{5}$ & 40 \\
CHI-4 & $998 \pm 6$ & $2.6 \times 10^{5}$ & 46 \\
\hline \multicolumn{4}{c}{ SD—Standard deviation. }
\end{tabular}

\subsection{X-ray Diffraction}

The diffractograms of the chitosan samples are shown in Figure 6. The characteristic peaks of chitosan centered at 10 and 20 degrees in $2 \theta$ corresponding to the crystallographic planes (002) and (101), respectively, are present in the diffractograms of all samples. The crystallinity index of chitosans was calculated from the diffractograms using Equation (6). It has been pointed out that this procedure might lead to an underestimation of CrI, since the contribution of the amorphous phase is overestimated. However, since the same procedure has been used for the all samples, the results can be used for comparison. The values listed in Table 3 indicate that $\mathrm{CrI}$ was around $40 \%$ for almost all chitosans. 


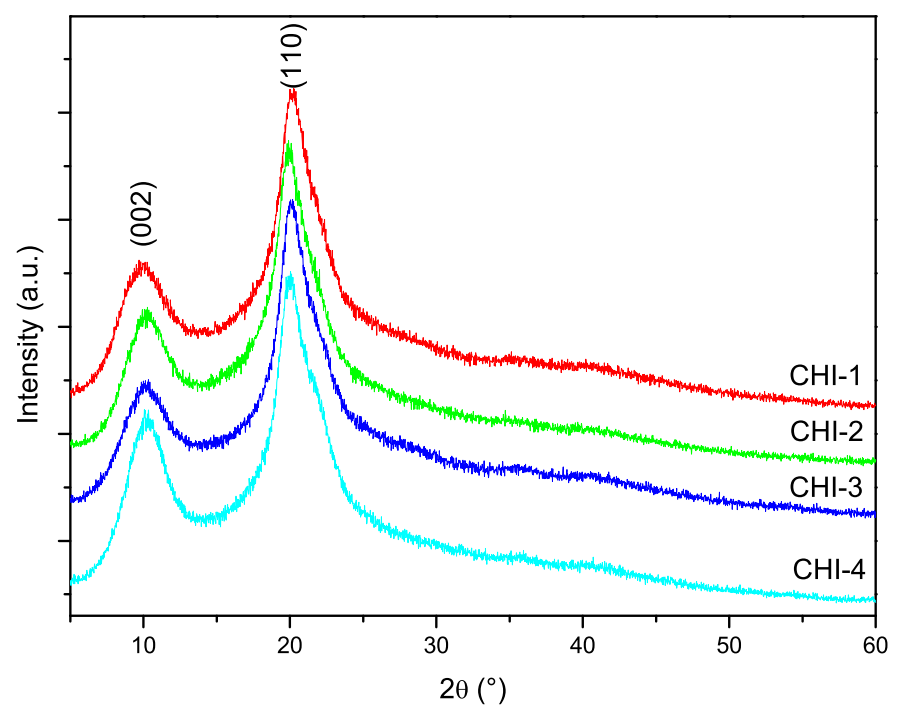

Figure 6. Powder X-ray diffraction patterns of chitosans prepared with the conditions listed in Table 1.

\section{Conclusions}

In the procedure developed in the present work, chitosan was obtained as a white powder with adequate physical-chemical properties: ash content below $0.063 \%$, and high solubility in $1 \%$ acetic acid, with insoluble contents of $0.62 \%$ or less. The deacetylation degrees achieved were above $90 \%$ and the crystallinity index were around $40 \%$. The molecular weight of chitosans were between 2.3 and $2.8 \times 10^{5} \mathrm{~g} / \mathrm{mol}$. The results obtained indicate that, with the present preparation procedure, chitosan samples with physical and chemical properties suitable for pharmaceutical applications are obtained.

Acknowledgments: We would like to thank CAPES and OPAS for their support.

Author Contributions: All authors contributed equally to planning and to execution this work.

Conflicts of Interest: The founding sponsors had no role in the design of the study; in the collection, analyses, or interpretation of data; in the writing of the manuscript, and in the decision to publish the results.

\section{Abbreviations}

The following abbreviations are used in this manuscript:

MDPI Multidisciplinary Digital Publishing Institute

DOAJ Directory of Open Access Journals

DA Acetylation Degree

EDS Energy Dispersive Spectroscopy

ASTM American Society for Testing and Materials

FTIR Fourier Transform Infrared Spectroscopy

UV UV-Visible Spectroscopy

XRD X-Ray Diffraction

WAXD Wide Angle X-Ray Diffraction

CrI Crystallinity Index

SEM Scanning Electron Microscope

SD Standard Deviation

OPAS Organization Pan American Health

CAPES Coordination for the Improvement of Higher Education Personnel 


\section{References}

1. Dash, M.; Chiellini, F.; Ottenbrite, R.M.; Chiellini, E. Chitosan-A versatile semi-synthetic polymer in biomedical applications. Prog. Polym. Sci. 2011, 36, 981-1014.

2. Vo, T.-S.; Ng, D.-H.; Kim, S.-K. Cosmeceutical compounds from marine sources. In Kirk-Othmer Chemical Technology of Cosmetics; Seidel, A., Bickford, M., Eds.; John Wiley \& Sons, Inc.: Hoboken, NJ, USA, 2013; pp. 483-499.

3. Khor, E.; Wan, A.C.A. Chitin: Fulfilling a Biomaterials Promise, 2nd ed.; Elsevier Ltd.: Waltham, MA, USA, 2013.

4. Bouhenna, M.; Salah, R.; Bakour, R.; Drouiche, N.; Abdi, N.; Grib, H.; Lounici, H.; Mameri, N. Effects of chitin and its derivatives on human cancer cells lines. Environ. Sci. Pollut. Res. 2015, 22, 15579-15586.

5. Ahmed, T.A.; Aljaeid, B.M. Preparation, characterization, and potential application of chitosan, chitosan derivatives, and chitosan metal nanoparticles in pharmaceutical drug delivery. Drug Des. Dev. Ther. 2016, 10, 483-507.

6. Sharp, R.G. A Review of the Applications of Chitin and Its Derivatives in Agriculture to Modify Plant-Microbial Interactions and Improve Crop Yields. Agronomy 2013, 3, 757-793.

7. Bautista-Banos, S.; Romanazzi, G.; Jiménez-Aparicio, A. (Eds.) Chitosan in the Preservation of Agricultural Commodities; Academic Press, Elsevier: Amsterdam, The Netherlands, 2016.

8. Luo, Y.; Wang, Q. Recent Advances of Chitosan and Its Derivatives for Novel Applications in Food Science. J. Food Process. Beverages 2013, 1, 1-13.

9. No, LH.K.; Meyers, S.P. Application of chitosan for treatment of wastewaters. Rev. Environ. Contam. Toxicol. 2000, 1, 1-27.

10. Peniche, C.; Argüelles-Monal, W. Chitosan Based Polyelectrolyte Complexes. In Natural and Synthetic Polymers: Challenges and Perspectives; Wiley-VCH: Weinheim, Germany, 2001; Volume 168, pp. 103-116.

11. Croisier, F.; Jérôme, C. Chitosan-based biomaterials for tissue engineering Eur. Polym. J. 2013, 49, $780-792$.

12. Agnihotri, S.A.; Mallikarjuna, N.N.; Aminabhavi, T.M. Recent advances on chitosan-based micro- and nanoparticles in drug delivery. J. Control. Release 2004, 100, 5-28.

13. Steinbüchel, A.; De Baets, S.; Vandamme, E.J. Biopolymers, Vol. 6. Polysaccharides II: Polysaccharides from Eukaryotes; Wiley-VCH: Weinheim, Germany, 2002.

14. Khoushab, F.; Yamabhai, M. Chitin Research Revisited. Mar. Drugs 2010, 8, 1988-2012.

15. Younes, I.; Rinaudo, M. Chitin and chitosan preparation from marine sources. Structure, properties and applications. Mar. Drugs 2015, 13, 1133-1174.

16. Chen, X.; Yang, H.; Yan, N. Shell Biorefinery: Dream or Reality? Chem. Eur. J. 2016, 22, 13402-13421.

17. Roberts, G.A.F. Chitin Chemistry; The Macmillan Press Ltd.: London, UK, 1992; pp. 54-61.

18. Brugnerotto, J.; Lizardi, J.; Goycoolea, F.; Argüelles-Monal, W.; Desbrieres, J.; Rinaudo, M. An infrared investigation in relation with chitin and chitosan characterization. Polymer 2001, 42, 3569-3580.

19. Qin, Y.; Lu, X.M.; Sun, N.; Rogers, R.D. Dissolution or extraction of crustacean shells using ionic liquids to obtain high molecular weight purified chitin and direct production of chitin films and fibers. Green Chem. 2010, 12, 968-971.

20. Setoguchi, T.; Kato, T.; Yamamoto, K.; Kadokawa, J.-I. Facile production of chitin from crab shells using ionic liquid and citric acid. Int. J. Biol. Macromol. 2012, 50, 861-864.

21. Beaney, P.; Lizardi-Mendoza, J.; Healy, M. Comparison of chitins produced by chemical and bioprocessing methods. J. Chem. Technol. Biotechnol. 2005, 80, 145-150.

22. Arbia, W.; Arbia, L.; Adour, L.; Amrane, A. Chitin extraction from crustacean shells using biological methods-A review. Food Technol. Biotechnol. 2013, 51, 12-25.

23. Synowiecki, J. The recovery of protein hydrolyzate during enzymatic isolation of chitin from shrimp Crangon processing discard. Food Chem. 2000, 68, 147-152.

24. Tsaih, M.L.; Chen, R.H. The effect of reaction time and temperature during heterogenous alkali deacetylation on degree of deacetylation and molecular weight of resulting chitosan. J. Appl. Polym. Sci. 2003, 88, 2917-2923.

25. Lertwattanaseri, T.; Ichikawa, N.; Mizoguchi, T.; Tanaka, Y.; Chirachanchai, S. Microwave technique for efficient deacetylation of chitin nanowhiskers to a chitosan nanoscaffold. Carbohydr. Res. 2009, 344, 331-335. 
26. Hamer, S.N.; Cord-Landwehr, S.; Biarnés, X.; Planas, A.; Waegeman, H.; Moerschbacher, B.M. Enzymatic production of defined chitosan oligomers with a specific pattern of acetylation using a combination of chitin oligosaccharide deacetylases. Sci. Rep. 2015, 5, 8716.

27. Allwin, S.I. ; Jeyasanta, K.I.; Patterson, J. Extraction of Chitosan from White Shrimp (Litopenaeus vannamei). Processing Waste and Examination of its Bioactive Potentials. Adv. Biol. Res. 2015, 9, 389-396.

28. Ploydee, E.; Chaiyanan, S. Production of High Viscosity Chitosan from Biologically Purified Chitin Isolated by Microbial Fermentation and Deproteinization. Int. J. Polym. Sci. 2014, 2014, 162173.

29. Hajji, S.; Younes, I.; Ghorbel-Bellaaj, O.; Hajji, R.; Rinaudo, M.; Nasri, M.; Jellouli, K. Structural differences between chitin and chitosan extracted from three different marine sources. Int. J. Biol. Macromol. 2014, 65, 298-306.

30. De Andrade, S.M.B.; Ladchumananandasivam, R.; da Rocha, B.G.; Belarmino, D.D.; Galvão, A.O. The Use of Exoskeletons of Shrimp Litopenaeus vanammei) and Crab (Ucides cordatus) for the extraction of Chitosan and Production of nanomembrane. Mater. Sci. Appl. 2012, 3, 495-508.

31. Moura, C.; Muszinski, P.; Schmidt, C.; Almeida, J.; Pinto, L. Quitina e quitosana produzidas a partir de resíduos de camarão e siri: avaliação do processo em escala piloto. Vetor Rio Grande 2006, 16, 37-45.

32. Lamarque, G.; Cretenet, M.; Viton, C.; Domard A. New Route of Deacetylation of $\alpha$ - and $\beta$-Chitins by Means of Freeze-Pump Out-Thaw Cycles. Biomacromolecules 2005, 6, 1380-1388.

33. Agência Nacional de Vigilância Sanitária Farmacopéia Brasileira; Anvisa: Brasilia, DF, Brazil, 2010.

34. ASTM International. F2103-11 Standard Guide for Characterization and Testing of Chitosan Salts as Starting Materials Intended for Use in Biomedical and Tissue-Engineered Medical Product Applications; ASTM International: West Conshohocken, PA, USA, 2011.

35. Rinaudo, M.; Milas, M.; Le Dung, P. Characterization of chitosan. Influence of ionic strength and degree of acetylation on chain expansion. Int. J. Biol. Macromol. 1993, 15, 281-285.

36. Domszy, J.G.; Roberts, G.A. Evaluation of infrared spectroscopic techniques for analysing chitosan. Macromol. Chem. Phys. 1985, 186, 1671-1677.

37. Muzzarelli, R.A.; Rocchetti, R. Determination of the degree of acetylation of chitosans by first derivative ultraviolet spectrophotometry. Carbohydr. Polym. 1985, 5, 461-472.

38. Osorio-Madrazo, A.; David, L.; Trombotto, S.; Lucas, J.-M.; Peniche-Covas, C.; Domard, A. Kinetics study of the solid-state acid hydrolysis of chitosan: Evolution of the crystallinity and macromolecular structure. Biomacromolecules 2010, 11, 1376-1386.

39. The European Pharmacopeia; C.o. Europe: Strasburg, France, 2007; pp. 1490-1491.

40. The United States Pharmacopeia; The United States Pharmacopeial Convention: Rockville, MD, USA, 2011; pp. 5361-5365.

41. Povea, M.B.; Monal, W.A.; Cauich-Rodríguez, J.V.; Pat, A.M.; Rivero, N.B.; Covas, C.P. Interpenetrated chitosan-poly(acrylic acid-co-acrylamide) hydrogels. Synthesis, characterization and sustained protein release studies. Mater. Sci. Appl. 2011, 2, 509-520.

42. Kumirska, J.; Czerwicka, M.; Kaczynski, Z.; Bychowska, A.; Brzozowski, K.; Thoming, J.; Stepnowski, P. Application of spectroscopic methods for structural analysis of chitin and chitosan. Mar. Drugs 2010, 8, $1567-1636$.

(C) 2017 by the authors. Licensee MDPI, Basel, Switzerland. This article is an open access article distributed under the terms and conditions of the Creative Commons Attribution (CC BY) license (http:/ / creativecommons.org/licenses/by/4.0/). 